\title{
Hip Osteoarthritis
}

National Cancer Institute

\section{Source}

National Cancer Institute. Hip Osteoarthritis. NCI Thesaurus. Code C34876.

Osteoarthritis of the hip joint. 